\title{
Experiment of Carbonate Dissolution: Implication for High Quality Carbonate Reservoir Formation in Deep and Ultradeep Basins
}

\author{
Zhiliang He, ${ }^{1,2}$ Qian Ding, ${ }^{1,2}$ Yujin Wo, ,,2 Juntao Zhang, ${ }^{1,2}$ Ming Fan, ${ }^{1,3}$ and Xiaojuan Yue \\ ${ }^{1}$ State Key Laboratory of Shale Oil and Gas Enrichment Mechanisms and Effective Development, Beijing 100083, China \\ ${ }^{2}$ Laboratory of Structural and Sedimentological Reservoir Geology, Petroleum Exploration and Production Research Institute, \\ SINOPEC, Beijing 100083, China \\ ${ }^{3}$ Wuxi Research Branch of Petroleum and Production Research Institute, SINOPEC, Wuxi 214151, China \\ ${ }^{4}$ China University of Petroleum-Beijing, Beijing 102249, China
}

Correspondence should be addressed to Qian Ding; dingqian.syky@sinopec.com

Received 26 February 2017; Revised 22 June 2017; Accepted 12 July 2017; Published 11 September 2017

Academic Editor: Keyu Liu

Copyright (c) 2017 Zhiliang He et al. This is an open access article distributed under the Creative Commons Attribution License, which permits unrestricted use, distribution, and reproduction in any medium, provided the original work is properly cited.

As the most frontiers in petroleum geology, the study of dissolution-based rock formation in deep carbonate reservoirs provides insight into pore development mechanism of petroleum reservoir space, while predicting reservoir distribution in deep-ultradeep layers. In this study, we conducted dissolution-precipitation experiments simulating surface to deep burial environments (open and semiopen systems). The effects of temperature, pressure, and dissolved ions on carbonate dissolution-precipitation were investigated under high temperature and pressure $\left(\sim 200^{\circ} \mathrm{C} ; \sim 70 \mathrm{Mpa}\right)$ with a series of petrographic and geochemical analytical methods. The results showed that the window-shape dissolution curve appeared in $75 \sim 150^{\circ} \mathrm{C}$ in the open system and $120 \sim 175^{\circ} \mathrm{C}$ in the semiopen system. Furthermore, the dissolution weight loss of carbonate rocks in the open system was higher than that of semiopen system, making it more favorable for gaining porosity. The type of fluid and rock largely determines the reservoir quality. In the open system, the dissolution weight loss of calcite was higher than that of dolomite with $0.3 \% \mathrm{CO}_{2}$ as the reaction fluid. In the semiopen system, the weight loss from dolomitic limestone prevailed with $0.3 \% \mathrm{CO}_{2}$ as the reaction fluid. Our study could provide theoretical basis for the prediction of high quality carbonate reservoirs in deep and ultradeep layers.

\section{Introduction}

Oil and gas formed in carbonate formations take up to $60 \%$ of the total oil and gas resources worldwide [1-3]. The deep carbonate reservoirs in China mainly distribute in Ordos, Tarim Basin of Ordovician, Sichuan Basin of Triassic, Permian, Carboniferous, Cambrian, and Sinian, and the depth of those reservoirs ranges from $3000 \mathrm{~m}$ to $8000 \mathrm{~m}$ $[4,5]$. The exploration practice on Well TS1 from Tarim Basin and well MS1 from Sichuan Basin found good dissolved pores in the ultradeep carbonate rocks with buried depths of 6,000 to $8400 \mathrm{~m}$ [6]. High quality dolomite reservoir was observed at $8408 \mathrm{~m}$ in well TS1 with porosity around $9.1 \%$. Dolostone with an average porosity of $12 \%$ was found in Sichuan Basin at $6000 \mathrm{~m} \mathrm{[7].} \mathrm{The} \mathrm{hydrocarbon} \mathrm{exploration} \mathrm{in} \mathrm{Tahe} \mathrm{Oil} \mathrm{field,}$
Jingbian Gas Field, Puguang Gas Field, Yuanba Gas Field, Anyue Gas Field, and other marine gas and oil fields indicated that marine carbonate, especially to deep layers, showed promising prospects.

After the deposition of carbonate sediments, it went through the penecontemporaneous stage, the early, the middle, and the late diagenetic stage, and the epigenetic stage. The valuable reservoir porosity of carbonate rocks is largely related to the fluid transformation process in the diagenetic process. Pore was destructed and developed in early meteoric zone diagenesis. In late stage of dissolution, porosity developed due to hydrocarbon maturation and destruction [8]. Based on the fluid source, the fluid in the carbonate fluidrock interaction can be divided into surface fluid, formation fluid, and deep source fluid. Based on the fluid source and 
interaction model, the geological fluid environment of carbonate reservoir formation can be divided into three categories: open environment, semiopen environment, and closed environment.

With the simulation experiment and numerical simulation, it is possible to clarify the relationship between the dissolution process of limestone and dolostone and temperature, pressure, and fluid. Plummer et al. [9], Busenberg and Plummer [10], and Sjöberg [11] investigated that the effects of $a_{\mathrm{H}^{+}}, p \mathrm{CO}_{2}$, and temperature on the dissolution rate of calcite and dolomite through simulation experiments. Fan et al. $[12,13]$ investigated the dissolution characteristics of different types of carbonate rocks in acetic acid/ $\mathrm{CO}_{2} / \mathrm{H}_{2} \mathrm{~S}$ solutions and found the positive relationship between dissolution strength and temperature. A high dissolution strength was thus maintained in a certain temperature range, and a "dissolution window" was formed. She et al. $[14,15]$ found that the dissolution rate of dolomite is close to micrite limestone. These studies have deepened the understanding of the formation and development of carbonate reservoirs. However, previous studies focused on the dissolution rate of carbonates in weak acidic fluid from room temperature to medium temperature $\left(\sim 150^{\circ} \mathrm{C}\right)$ and its dissolution control factors; few attentions were paid on the dissolution patterns of carbonate rock/carbonate mineral-fluid reactions under different system and high temperature/pressure [16-20]. In this study, the dissolution process with carbonate samples/minerals under different fluid environment and different fluid/rock ratio was carried out using a self-made simulation experimental instrument, and the favorable fluid environment for developing high quality carbonate reservoir was discussed.

\section{Experiments}

The carbonate and fluid interaction can be regarded as a solid-gas-liquid three-phase coexisting reaction system. In the system, carbonate rock served as the solid phase for dissolution or precipitation; the liquid and gas filled in the porosity served as the fluid. The main factors influencing the interaction between solid and liquid are temperature, pressure, $\mathrm{pH}$, fluid/solid ratio, mineral surface structure, reaction surface area, and so on [21]. The burial depth determines the temperature and pressure of the system. The reaction between carbonate mineral and fluid is as follows:

$$
\mathrm{MCO}_{3}+\mathrm{H}_{2} \mathrm{O}+\mathrm{CO}_{2} \longleftrightarrow \mathrm{M}^{2+}+2 \mathrm{HCO}_{3}^{-}
$$

$\mathrm{M}$ represents alkali metal element (Ca, $\mathrm{Mg}$, etc.). During reaction, $\mathrm{CaCO}_{3}$ or $\mathrm{CaMg}\left(\mathrm{CO}_{3}\right)_{2}$ dissolved and $\mathrm{Ca}^{2+}$ and $\mathrm{Mg}^{2+}$ entered into the fluid. The reaction progress can be monitored quantitatively by the change of metal cation concentration or the mineral weight loss before and after the reaction.

2.1. Experiment Setting. This experiment is carried out on carbonate reservoir dissolution rate instrument which is designed and manufactured by our lab (Figure 1) [12, 22, 23]. An electrical heater was used to heat the reactor. The temperature of the reactor was monitored and controlled

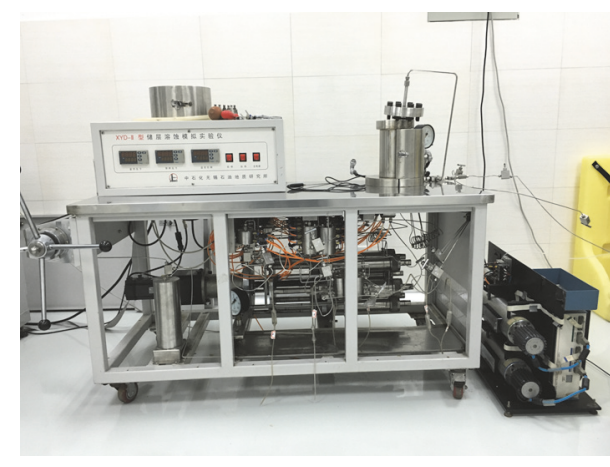

FIGURE 1: Carbonate reservoir dissolution simulation instrument (Type XYD-II).

by a temperature sensor (Pt100). The designed temperature and pressure of the instrument are $250^{\circ} \mathrm{C}$ and $70 \mathrm{Mpa}$. The pressure and flow rate of the reaction system are controlled by a constant pressure constant current pump. Surface structure was observed by scanning electron microscope (SEM; Zeiss EVO MA 10, Germany); the concentrations of $\mathrm{Ca}^{2+}$ and $\mathrm{Mg}^{2+}$ before and after the reaction were measured by ICP-OES (Agilent, 715 OES, USA) with detection limit of $0.3 \mu \mathrm{g} / \mathrm{L}$ and $0.1 \mu \mathrm{g} / \mathrm{L}$, respectively. The type and constituents of the minerals were measure by X-ray diffractometer (XRD; Bruker D8, Germany).

2.2. Experiment Steps. During the experiment, the temperature and pressure of the reactor were gradually raised to the setting values. The fluid was pressurized in the reservoir tank and then flowed into the high-temperature and highpressure reactor through the pipeline (Hastelloy). Six parallel quartz reaction tubes could be placed in the reactor. The fluid first flowed through the tube and then react with the carbonate sample. Following (1), the weight loss of the carbonate minerals during the reaction could quantitatively describe the magnitude of dissolution process.

Following a geothermal gradient of $2.5^{\circ} \mathrm{C} / 100 \mathrm{~m}$, the temperature and pressure from earth surface to the formation depth $(7000 \mathrm{~m})$ ranged from $25 \sim 200^{\circ} \mathrm{C}$ and $1 \sim 70 \mathrm{Mpa}$, respectively. The temperature of the reactor was heated gradually around $5^{\circ} \mathrm{C} / \mathrm{min}$. The fluid flow rates were set at $1 \mathrm{ml} / \mathrm{min}$ and $0 \mathrm{ml} / \mathrm{min}$ for the open and the semiopen geological fluid system, respectively (Table 1 ). The reaction time for each temperature/pressure set was 3 to 4 hours till the calcium and magnesium ions concentrations in the fluid no longer changed and then extended for two more hours to ensure that the equilibrium of the fluid-rock interaction was reached. When the reaction was completed, the calcium and magnesium ions in the fluid were measured and the dissolution rate was determined by weighing the mass loss of the samples.

At the end of the experiment, the dissolution characteristics of the two kinds of fluid systems and various carbonate samples with temperature and pressure were investigated by measuring the change of dissolution weight loss and the change of ion concentrations. 
TABLE 1: Experimental conditions.

\begin{tabular}{llccc}
\hline & Reaction fluid & $\begin{array}{c}\text { Temperature } \\
\left({ }^{\circ} \mathrm{C}\right)\end{array}$ & Water/rock ratio & $\begin{array}{c}\text { Flow rate } \\
(\mathrm{ml} / \mathrm{min})\end{array}$ \\
\hline Open system & $0.3 \% \mathrm{CO}_{2}$ solution & $35^{\circ} \mathrm{C}$ to $200^{\circ} \mathrm{C}$ & $1: 30$ & 1 \\
Semiopen system & $0.3 \% \mathrm{CO}_{2}$ solution & $35^{\circ} \mathrm{C}$ to $200^{\circ} \mathrm{C}$ & $1: 1$ & 0 \\
\hline
\end{tabular}

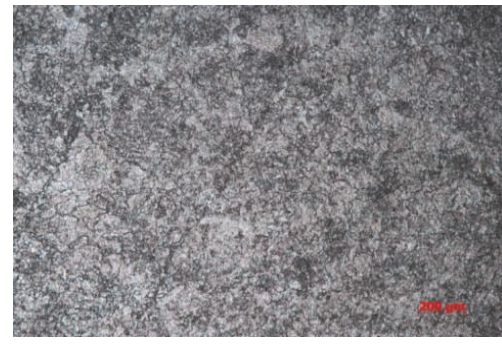

(a)

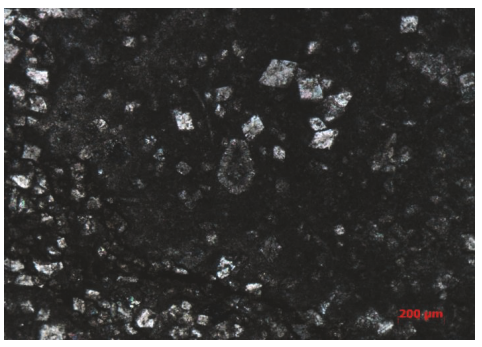

(b)

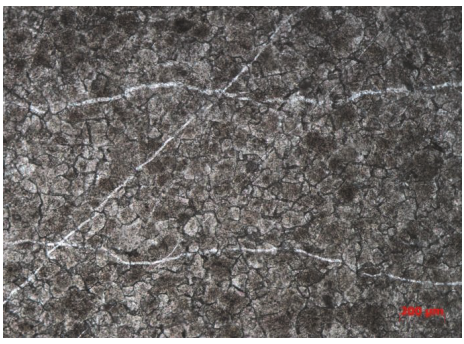

(c)

FIGURE 2: Carbonate rock sample types: (a) micritic limestone; (b) dolomitic limestone; (c) fine crystalline dolostone.

2.3. Experimental Subject. In this study, samples were standard calcite mineral, standard dolomite mineral, and micritic limestone samples from Ordovician Pingliang Formation, dolomitic limestone samples, and fine crystalline dolostone samples from Ordovician Majiagou Formation. The microscopic characteristics of the samples are shown in Figure 2. The collecting positions and formations of the samples are listed in Table 2. The mineral composition and content of the carbonate samples are listed in Table 3.

The samples were crushed into particles of $2.8 \mathrm{~mm}$ to $4.2 \mathrm{~mm}$ in diameter to fit the sample tube. The samples were ultrasonically cleaned with deionized water and dried in the oven at $105^{\circ} \mathrm{C}$ for 24 hours. $\mathrm{CO}_{2}$ aqueous solution was selected as the acidic fluid medium, to simulate the in situ acidic fluid environment [24]. The mass fraction of $\mathrm{CO}_{2}$ in the aqueous solution is $0.3 \%$ with $\mathrm{pH}$ of 4.2 .

\section{Results and Discussion}

3.1. Carbonate Weight Loss in the Open System. In the open system simulation, the dissolution of calcite generally exceeded that of dolomite, so as limestone and dolostone (Figure 3). The dissolution weight loss of each carbonate sample showed a dissolution window, during which the weight loss first ascends and then declines along with rising temperature $[12,22,23,25]$. The temperature that showed the dissolution window ranged from $35^{\circ} \mathrm{C}$ to $150^{\circ} \mathrm{C}$. The dissolution weight loss of the standard calcite sample increased between $35^{\circ} \mathrm{C}$ and $100^{\circ} \mathrm{C}$, reached the peak value at $100^{\circ} \mathrm{C}$, and then declined slowly. For the standard dolomite sample, the range when dissolution weight loss increased was between $35^{\circ} \mathrm{C}$ and $125^{\circ} \mathrm{C}$, and the maximum dissolution weight loss was reached at $125^{\circ} \mathrm{C}$. The response time of dolomite on temperature variation was slower than that of calcite, and the maximum dissolution weight loss of calcite was twice of the dolomite. These results indicated that the calcite was dissolute more than that of dolomite in the open environment and

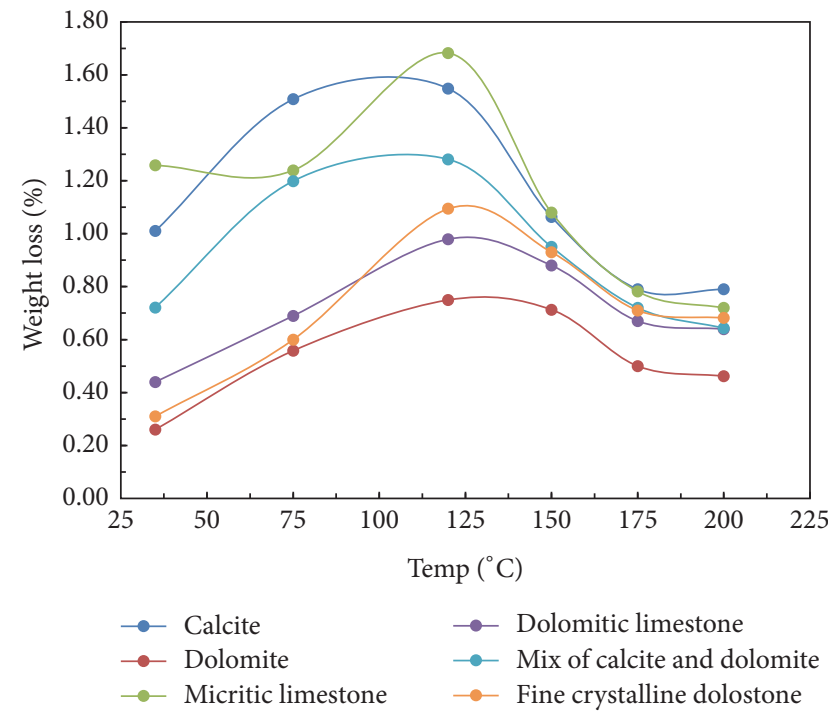

FIgURE 3: The relationship between carbonate dissolution weight loss and temperature in the open system.

was consistent with the former study carried out in the open system [23]. Through thermodynamic simulations, Huang et al. [26] found that carbonate minerals in the depth of less than 700 meters of the formation tend to dissolve, and Zhu et al. [27] found that the dissolution performance of carbonate rocks increased first and then decreased with the increase of temperature. The results in this study are in accordance with the above simulations.

3.2. Carbonate Weight Loss in the Semiopen System. In the semiopen system simulation, the dissolution weight loss of dolomitic limestone was the largest among all the samples. The dissolution weight loss of calcite was higher than that of dolomite for the whole temperature range. Limestone and dolomite shared similar dissolution weight losses between 
TABLE 2: Collecting location of the samples.

\begin{tabular}{lccc}
\hline Sample number & Sample name & Lithology & Formation \\
\hline C1 & Calcite standard mineral & Calcite & - \\
D1 & Dolomite standard mineral & Dolomite & - \\
A1 & XLG-O 2 P-16 & Micritic limestone & Ordovician Pingliang Formation \\
A2 & TWD-O $\mathrm{O}_{2}$ P 7 & Dolomite limestone & Ordovician Tiewadian Formation \\
A3 & Mixed standard mineral & Half calcite, half dolomite & - \\
A4 & XF3 well & Fine crystalline dolostone & Ordovician Majiagou Formation \\
\hline
\end{tabular}

TABLE 3: Components and contents of the minerals.

\begin{tabular}{lccccc}
\hline \multicolumn{2}{l}{ Sample number Calcite } & Dolomite & Quartz & Pyrite & Clay mineral \\
\hline C1 & $100 \%$ & - & - & - & - \\
D1 & - & $100 \%$ & - & - & - \\
A1 & $95.8 \%$ & - & $2.3 \%$ & $1.9 \%$ & - \\
A2 & $68.2 \%$ & $26.6 \%$ & $2.3 \%$ & - & $2.9 \%$ \\
A3 & $50 \%$ & $50 \%$ & - & - & - \\
A4 & - & $90.1 \%$ & $4.2 \%$ & $2.5 \%$ & $3.2 \%$ \\
\hline
\end{tabular}

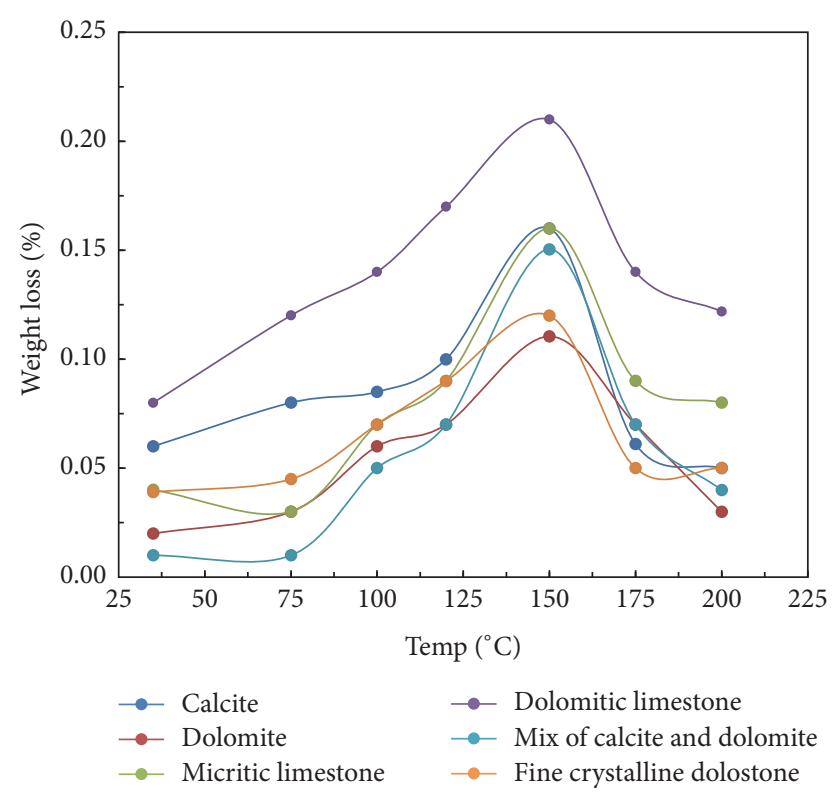

FIGURE 4: The relationship between carbonate dissolution weight loss and temperature in the semiopen system.

$35^{\circ} \mathrm{C} \sim 125^{\circ} \mathrm{C}$, and the dissolution rate of the former exceeded the latter when temperature was higher than $125^{\circ} \mathrm{C}$. The dissolution weight loss of all the samples came to the peak around $150^{\circ} \mathrm{C}$. The highest dissolution weight loss of calcite is about 1.5 times that of dolomite. The temperature range for the dissolution window was from $120^{\circ} \mathrm{C}$ to $175^{\circ} \mathrm{C}$. The dissolution window in the semiopen system appeared at higher temperature/pressure than that in the open system (Figure 4).
In the semiopen system, dolomitic limestone (with a dolomite content $<30 \%$ ) had a higher weight loss than other carbonate samples. Taylor et al. [28] also found that the dissolution weight loss of the limestone from Kluff formation with a dolomite content of 30-40\% was the largest in $1 \mathrm{M} \mathrm{HCl}$ solution and at room temperature. Davis et al. [29] suggested that $\mathrm{Mg}^{2+}$ generated from dolomite dissolution destroyed the internal crystal structure of calcite and enhanced the dissolution of calcite. It is also observed in the field that the dolomitized limestone reservoirs are generally well developed for the dissolution of the pores.

The simulation experiment of the semiopen system is close to the actual deep-ultradeep carbonate stratum. The opening of the fault systems associated with episodic tectonics or the specific fluid developed from adjacent formations such as $\mathrm{CO}_{2}$, organic acids which form hydrocarbon generation, or $\mathrm{H}_{2} \mathrm{~S}$ from TSR could make it favorable for the fluid entering the fault or fractures to react with carbonate rock. The water/rock ratio is relatively small due to the small amount of the liquid. In that case, the fluid became supersaturation in a short time during the reaction, following the equilibrium of the dissolution/precipitation process. Such short period of reactions affected little on creating porosity but could maintain the preexisting pores formed in the open system and prevent the porosity loss through cementation.

In this study, the average weight loss of the standard calcite sample in the open system was 14 times larger than that of the semiopen system. For the standard dolomite samples, the average weight loss in the open system was 11 times of that in the semiopen system. As a result, the dissolution weight loss of carbonate rocks in the open system was higher under the same temperature and pressure conditions (corresponding to the burial depth), which is also favorable for porosity creation (Figure 5).

In the dissolution process of carbonate minerals, $\mathrm{H}^{+}$ in the solution diffused into the diffusion boundary layer between the mineral and the solution and reacted with the surface of the mineral. $\mathrm{Ca}^{2+}$ and $\mathrm{Mg}^{2+}$, as the reaction product, diffused from the mineral surface into the solution. The thickness of the boundary layer determines the diffusion time and the reaction rate. The dissolution rate could be limited. When the flow rate of the fluid was low, a relatively thicker diffusion boundary layer was made, and the slow mass transfer velocity became the limiting factor of a higher dissolution rate and vice versa [30-32]. In the open system, the stronger hydrodynamic condition and a thinner DBL than 


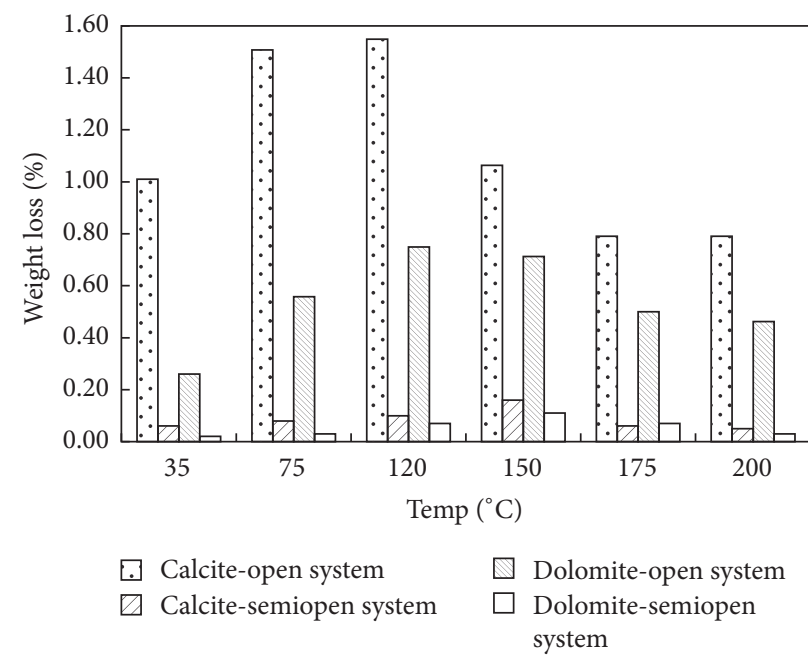

FIGURE 5: The comparison of dissolution weight loss of carbonate rock samples in the open systems and semiopen systems.

that in the semiopen system could lead to a higher diffusion rate.

When the $\mathrm{pH}$ of fluid was below 4 , the mineral dissolution rate was proportional to $\mathrm{H}^{+}$concentration $[33,34]$. The open fluid system is continually replenished with fresh acidic fluid ( $\mathrm{pH} \sim 4$ ) during the reaction. Nevertheless, the total amount of fluid in the semiopen fluid system was relatively small and the average $\mathrm{pH}$ of the fluid increased to $\sim 5.45$ after $\mathrm{H}^{+}$ depletion. Thus, a lower $\mathrm{pH}$ of the fluid could guarantee the open system with a higher reaction rate. As a result, both the higher diffusion rate and the reaction rate indicated that the dissolution of carbonate rocks in the open system, with a larger total dissolution amount, was more significant than those in the semiopen system.

In addition, simulation experiments of water-rock interaction of carbonate rocks in the closed system showed that the whole carbonate rock tended to precipitation and cementation as temperature and pressure increased [35]. However, we also observed that a few single points tended to dissolve, which indicated a dynamic equilibrium of dissolution/precipitation process in the reaction. Since water/rock ratio is quite small in the closed system, precipitation merely had an influence on the whole porosity status.

3.3. Surface Observation of the Carbonate Samples. The carbonate samples were observed by scanning electron microscopy (SEM) before and after the reaction in the open system. The characteristics of carbonate dissolution are as follows: the calcite surface was flat before the reaction (Figure 6(a)), and then small dissolved pores were formed along the calcite cleavage surface or the weak point on the surface (Figure 6(b)). Some newly white mineral precipitated on the surface, which was later identified as $\mathrm{CaCO}_{3}$ by Energy Dispersive Spectrometer (Figure 6(c)). Dolomite dissolved mainly on the crystal edge from rhombus to ellipsoid (Figure 6(d)). Small pores formed on the dolomite crystal edge were then connected to form larger pores (Figures 6(e) and 6(f)). Herman and White [36] observed the selective dissolution of dolomite along the grain edge. The initial interface of the fluid and the rock determines the interface morphology after dissolution. Generally, the dissolution was extended and connected along the contact surface of the mineral cleavage, the fracture, and the weak points.

\subsection{Characteristics of Different Fluid Environments}

3.4.1. Open Geological Fluid System. When we applied the experimental results to the corresponding actual geological fluid system of which deep-ultradeep carbonate reservoir was formed, (1) open environment with a higher water/rock ratio would lead to a fluid with unsaturated $\mathrm{CaCO}_{3}$. In that case, the water-rock reaction kept moving towards the dissolution direction. New pores were formed, and the original pores or fractures were expanded. The new formed pores offered a larger surface area for the dissolution reaction. Carbonate strata continue to dissolve into scaled reservoir, along with the development of large pore and fracture system.

In the geological history, open geological environment mainly existed in the penecontemporaneous stage of longterm exposure sedimentary diagenesis such as reef, beach, and tidal flat with frequent exposures or the epigenesis stage of tectonic uplift such as near-surface karst environment and deep cycle fresh water dissolution environment. The long term and large scale of such dissolution could form considerable storage space. Despite the filling effect from mechanical, chemical, or biochemical processes, open environment is the main forming environment for high quality carbonate reservoirs. In addition, the scale and quality of the reservoir were further determined by the composition and structure of the carbonate rock, the interaction intensity and time of fluid, and the filling patterns and magnitude. For example, the quality of late karst reservoir may be degraded due to the effects of over dissolution and filling.

3.4.2. Semiopen Geological Fluid Environment. The water/ rock ratio in the semiopen geological fluid system was relatively small. The fluid was prone to rapidly reach saturation or supersaturation state during the reaction. There was a dynamic equilibrium of dissolution/precipitation process between the fluid and the rock. Mineral dissolves and precipitates along the fluid flow pathway simultaneously. Some preexisting porosity may be expanded while some porosity may get cementation by calcite and dolomite.

In geological history, such environment is characterized by periodic fault, active fold, and special fluid event during basin evolution, which change the original fluid environment and break the chemical balance inside the formation to form a new fluid environment. As a result, episodic fluid-rock interaction happened. The exchange of material and energy in the formation would cause a series of processes including dissolution, metasomatism, dolomitization, recrystallization, and cementation and lead to the increase/decrease of porosity. Along with burial process, hydrocarbon generation, BSR, and TSR occurred in the strata, and some acid/alkali fluid may also enter the carbonate formation along with magmatic activity to form a new fluid environment and alter the storage 


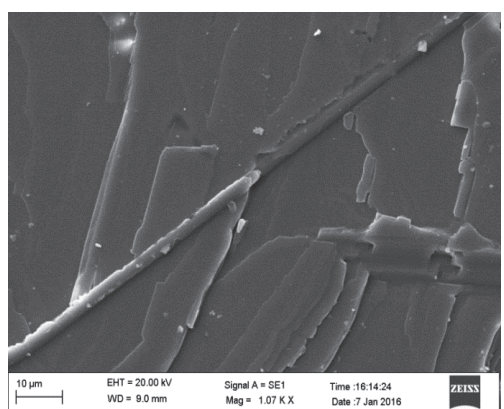

(a)

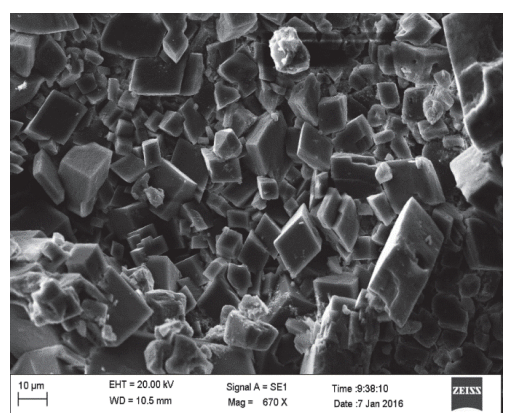

(d)

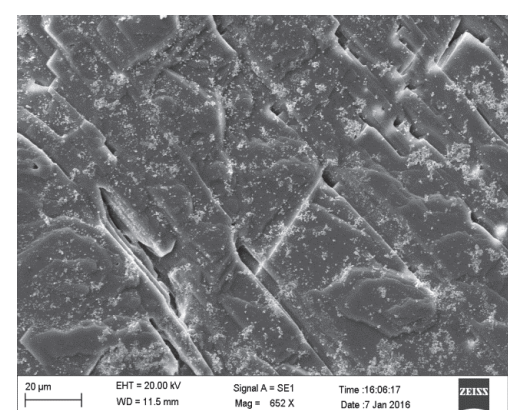

(b)

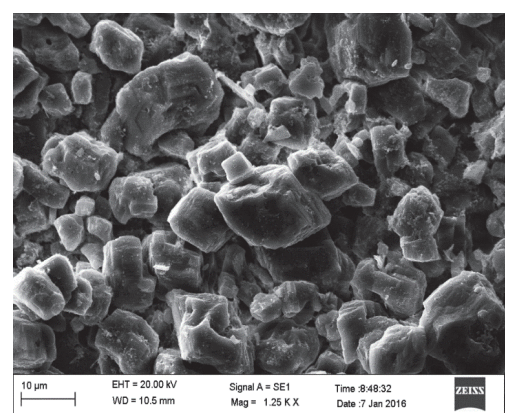

(e)

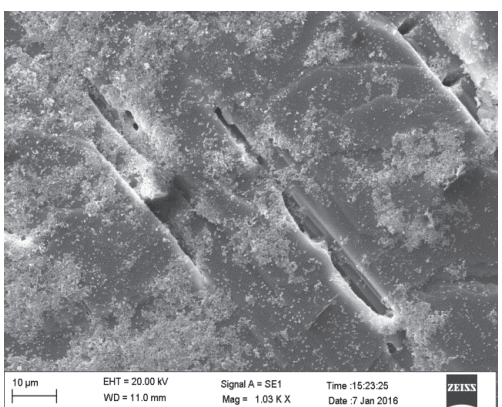

(c)

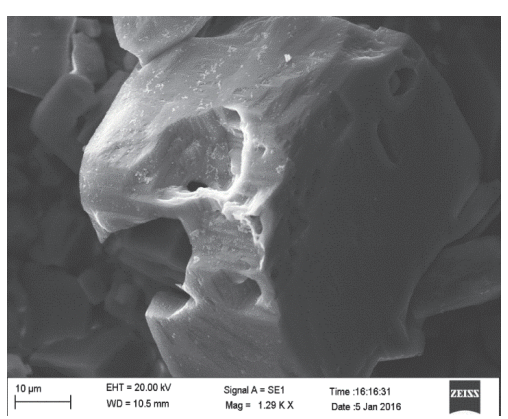

(f)

FIGURE 6: Surface morphology of the carbonate samples before and after the dissolution experiment: (a) calcite sample before dissolution; (b) dissolution fractures on the calcite surface; (c) expanded dissolution fracture after dissolution; (d) dolomite before the dissolution; (e) dolomite dissolved on the edge; (f) etch pits on the dolomite surface.

space. Chemical aggressive fluid during fluid-rock interaction, charged with $\mathrm{CO}_{2}, \mathrm{H}_{2} \mathrm{~S}$, organic acids, mainly came from organic matter maturation, hydrocarbon degradation, TSR, and BSR $[24,37,38]$. Those fluids could significantly dissolve the rock and enhance porosity [39, 40]. Moreover, some semiopen environment such as strong tectonic-hydrothermal movement could also form high quality carbonate reservoirs. For example, scaled hydrothermal dolostone reservoir is one of the key oil and gas exploration areas.

3.4.3. Closed Geological Fluid Environment. The remaining pore water in the closed geological fluid system was saturated, and the fluid-rock interaction reached an equilibrium state. There was no scaled dissolution or precipitation, and the preexisting porosity was maintained. Although fluid flow was limited, changes in burial depth may break the reaction equilibrium by temperature or pressure change. Minor precipitation, dissolution, or recrystallization would appear along with the change of burial depth, but porosity was barely altered in this environment. The main function of a closed environment is the maintenance of reservoir space. The closed fluid environment requires a stable tectonic background and good cap conditions, which are the foundation and prerequisite of oil and gas accumulation, transformation, adjustment, and preservation.

In summary, open and semiopen fluid environment are the key to the formation of reservoir space, and closed fluid environment is essential to the maintenance of reservoir space.

\section{Conclusions}

In this study, we reached the following understandings through the comprehensive analysis of the experiments results:

(1) Open is the key. Almost all the high quality reservoirs had experienced one or more open or semiopen geologic fluid environments in the geological evolution history. Long-term precipitation leaching during penecontemporaneous stage and epigenesis stage and acid dissolution in the middle and late stages of deep burial diagenesis could significantly improve the physical properties of the reservoirs.

(2) The type of the fluid and rock determines the dissolution rate and reservoir quality. The flow pattern, intensity, and reaction time of the fluid determine the dissolution strength and the dissolution rate. The structure, composition, and contact surface of rock affect the quality of the reservoir. The various channel types of the fluid flow could form reservoir space such as dissolution pores, fractures, and holes.

(3) Closed geological fluid environment is essential for the preservation of preexisting reservoir space. If the preexisting pores of the carbonate reservoirs were well formed in the early diagenesis stage, the deepultradeep closed environment could provide effective 
preservation conditions. The burial or uplifting process of the formation will change the system temperature and pressure and lead to microcirculation of the fluid in the reservoir. Although the migration and minor adjustment of the materials may occur, the porosity barely changed along with the obvious variation of permeability and heterogeneity.

\section{Conflicts of Interest}

The authors declare that they have no conflicts of interest.

\section{Acknowledgments}

The assistance of Dr. Ming Xue is acknowledged. The help on the experiment and reference material from Dr. Donghua You, Dr. Shoutao Peng, and Dr. Lingjie Yu is acknowledged. This work is supported by Strategic Priority Research Program of the Chinese Academy of Sciences (Grant no. XDA14010201) and National Natural Science Foundation of China (Grants no. 41702134 and no. U1663209).

\section{References}

[1] Z. R. Beydoun, "Arabian plate oil and gas: why so rich and so prolific?" Episodes, vol. 21, no. 2, pp. 74-81, 1998.

[2] T. P. Burchette, "Carbonate rocks and petroleum reservoirs: a geological perspective from the industry," Geological Society Special Publication, vol. 370, no. 1, pp. 17-37, 2012.

[3] H. G. Machel, M. L. Borrero, E. Dembicki, H. Huebscher, L. Ping, and Y. Zhao, "The grosmont: the world's largest unconventional oil reservoir hosted in carbonate rocks," Geological Society Special Publication, vol. 370, no. 1, pp. 49-81, 2012.

[4] Y. Ma, X. Cai, and P. Zhao, "The research status and advances in porosity evolution and diagenesis of deep carbonate reservoir," Earth Science Frontiers, vol. 18, no. 4, pp. 181-192, 2011.

[5] Z. He, X. Jin, and Y. Wo, "Hydrocarbon accumulation characteristics and exploration domains of ultra-deep marine carbonate in China," China Petroleum Exploration, vol. 21, no. 1, pp. 3-14, 2016.

[6] C. Jiao, Z. He, X. Xing, H. Qing, B. He, and C. Li, “Tectonic hydrothermal dolomite and its significance of reservoirs in Tarim basin," Acta Petrologica Sinica, vol. 27, no. 1, pp. 277-284, 2011.

[7] G. Zhu, S. Zhang, Y. Liang, Y. Ma, J. Dai, and G. Zhou, "Dissolution and alteration of the deep carbonate reservoirs by TSR: an important type of deep-buried high-quality carbonate reservoirs in Sichuan basin," Acta Petrologica Sinica, vol. 22, no. 8, pp. 2182-2194, 2006.

[8] P. W. Choquette and N. P. James, "Diagenesis\# 12. Diagenesis in Limestones-3. The deep burial environment," Geoscience Canada, vol. 14, no. 1, pp. 3-35, 1987.

[9] L. N. Plummer, T. M. L. Wigley, and D. L. Parkhurst, "The kinetics of calcite dissolution in $\mathrm{CO}_{2}$-water systems at 5 to $60^{\circ} \mathrm{C}$ and 0.0 to $1.0 \mathrm{~atm} \mathrm{CO}_{2}$," American Journal of Science, vol. 278, no. 2, pp. 179-216, 1978.

[10] E. Busenberg and L. N. Plummer, "The kinetics of dissolution of dolomite in $\mathrm{CO}_{2}-\mathrm{H}_{2} \mathrm{O}$ systems at 1.5 to $65^{\circ} \mathrm{C}$ and 0 to $1 \mathrm{~atm}$ $\mathrm{PCO}_{2}$," American Journal of Science, vol. 282, no. 1, pp. 45-78, 1982.
[11] E. L. Sjöberg, "Kinetics and mechanism of calcite dissolution in aqueous solutions at low temperatures," in Stockholm Contributions in Geology Stockholm, vol. 92, Almqvist Wiksell, 1978.

[12] M. Fan, X. Jiang, and W. Liu, "Dissolution of carbonate rocks in $\mathrm{CO}_{2}$ solution under the different temperature," Acta Sedimentologica Sinica, vol. 25, no. 6, pp. 825-830, 2007.

[13] M. Fan, Z. He, and Z. Li, "Dissolution window of carbonate rocks and its geological significance," Oil and Gas Geology, vol. 32, no. 4, pp. 499-505, 2011.

[14] M. She, Y. Zhu, A. Shen, X. Zheng, and X. He, "Simulation experiment for the dissolution of carbonate rocks of the Yingshan formation on the northern slope of Tazhong uplift," Carsolgica Sinica, vol. 31, no. 3, pp. 234-239, 2012.

[15] M. She, J. Shou, and A. Shen, "Experimental simulation of dissolution for carbonate rocks in organic acid under the conditions from epigenesis to deep burial environments," Geochimica, vol. 43, no. 3, pp. 276-286, 2014.

[16] J. W. Morse and R. S. Arvidson, "The dissolution kinetics of major sedimentary carbonate minerals," Earth-Science Reviews, vol. 58, no. 1-2, pp. 51-84, 2002.

[17] O. S. Pokrovsky, S. V. Golubev, and J. Schott, "Dissolution kinetics of calcite, dolomite and magnesite at $25^{\circ} \mathrm{C}$ and 0 to 50 atm $p \mathrm{CO}_{2}$," Chemical Geology, vol. 217, no. 3-4, pp. 239-255, 2005.

[18] O. S. Pokrovsky, S. V. Golubev, J. Schott, and A. Castillo, "Calcite, dolomite and magnesite dissolution kinetics in aqueous solutions at acid to circumneutral $\mathrm{pH}, 25$ to $150^{\circ} \mathrm{C}$ and 1 to $55 \mathrm{~atm}$ $\mathrm{pCO}_{2}$ : new constraints on $\mathrm{CO}_{2}$ sequestration in sedimentary basins," Chemical Geology, vol. 265, no. 1-2, pp. 20-32, 2009.

[19] L. N. Plummer and T. M. L. Wigley, "The dissolution of calcite in $\mathrm{CO}_{2}$-saturated solutions at $25^{\circ} \mathrm{C}$ and 1 atmosphere total pressure," Geochimica et Cosmochimica Acta, vol. 40, no. 2, pp. 191-202, 1976.

[20] L. N. Plummer and E. Busenberg, "The solubilities of calcite, aragonite and vaterite in $\mathrm{CO}_{2}-\mathrm{H}_{2} \mathrm{O}$ solutions between 0 and $90^{\circ} \mathrm{C}$, and an evaluation of the aqueous model for the system $\mathrm{CaCO}_{3}-\mathrm{CO}_{2}-\mathrm{H}_{2} \mathrm{O}$," Geochimica et Cosmochimica Acta, vol. 46, no. 6, pp. 1011-1040, 1982.

[21] S. L. Brantley and C. F. Conrad, "Analysis of rates of geochemical reactions," in Kinetics of Water-Rock Interaction, S. L. Brantley, J. D. Kubicki, and A. F. White, Eds., Springer, New York, NY, USA, 2008.

[22] X. Jiang, S. Wang, and M. Fan, "Study of simulation experiment for carbonate rocks dissolution in burial diagenetic environment," Petroleum Geology and Experiment, vol. 30, no. 6, pp. 643-647, 2008.

[23] M. Fan, K. Hu, and X. Jiang, "Effect of acid fluid on carbonate reservoir reconstruction," Geochimica, vol. 38, no. 1, pp. 20-26, 2009.

[24] S. J. Mazzullo and P. M. Harris, "An overview of dissolution porosity development in the deep-burial environment, with examples from carbonate reservoirs in the permian basin," in Permian Basin Plays-Tomorrow's Technology Today, M. P. Candelaria, Ed., West Texas Geological Society Publication, Midland, Texas, Tex, USA, 1991.

[25] Z. He, X. Wei, and Y. Qian, "Forming mechanism and distribution prediction of quality marine carbonate reservoirs," Oil and Gas Geology, vol. 32, no. 4, pp. 489-498, 2011.

[26] S. Huang, K. Huang, X. Zhang, L. Liu, and Q. Zhong, "Chemical thermodynamics foundation of retrograde solubility for carbonate: solution media related to $\mathrm{CO}_{2}$," Journal of Chendu University of Technology, vol. 36, no. 5, pp. 457-464, 2009. 
[27] D. Zhu, Z. Jin, and W. Hu, "Hydrothermal alteration dolomite reservoir in Tazhong area," Acta Petrolei Sinica, vol. 30, no. 5, pp. 698-704, 2009.

[28] K. C. Taylor, H. A. Nasr-El-Din, and S. Mehta, "Anomalous acid reaction rates in carbonate reservoir rocks," SPE Journal, vol. 11, no. 4, pp. 488-496, 2006.

[29] K. J. Davis, P. M. Dove, and J. J. De Yoreo, “The role of $\mathrm{Mg}^{2+}$ as an impurity in calcite growth," Science, vol. 290, no. 5494, pp. 1134-1137, 2000.

[30] W. Dreybrodt, J. Lauckner, L. Zaihua, U. Svensson, and D. Buhmann, "The kinetics of the reaction $\mathrm{CO}_{2}+\mathrm{H}_{2} \mathrm{O} \rightarrow \mathrm{H}^{+}$ $+\mathrm{HCO}_{3}^{-}$as one of the rate limiting steps for the dissolution of calcite in the system H2O-CO2-CaCO3," Geochimica et Cosmochimica Acta, vol. 60, no. 18, pp. 3375-3381, 1996.

[31] R. Orton and P. R. Unwin, "Dolomite dissolution kinetics at low pH: a channel-flow study," Journal of the Chemical Society, Faraday Transactions, vol. 89, no. 21, pp. 3947-3954, 1993.

[32] Z. Liu and D. Wolfgang, "Kinetics and rate-limiting mechanisms of dolomite dissolution at various $\mathrm{CO}_{2}$ partial pressures," Science in China, Series B: Chemistry, vol. 44, no. 5, pp. 500-509, 2001.

[33] E. L. Sjöberg and D. T. Rickard, "Calcite dissolution kinetics: surface speciation and the origin of the variable $\mathrm{pH}$ dependence," Chemical Geology, vol. 42, no. 1-4, pp. 119-136, 1984.

[34] R. A. Berner and J. W. Morse, "Dissolution kinetics of calcium carbonate in sea water; IV, Theory of calcite dissolution," American Journal of Science, vol. 274, no. 2, pp. 108-134, 1974.

[35] Y. Yang, B. Liu, and S. Qin, "Re-recognition of deep carbonate dissolution based on the observation of in-situ simulation experiment," Acta Scientiarum Naturalium Universitatis Pekinensis, vol. 50, no. 2, pp. 316-322, 2014.

[36] J. S. Herman and W. B. White, "Dissolution kinetics of dolomite: effects of lithology and fluid flow velocity," Geochimica et Cosmochimica Acta, vol. 49, no. 10, pp. 2017-2026, 1985.

[37] R. Sassen and C. H. Moore, "Framework of hydrocarbon generation and destruction in eastern smackover trend," American Association of Petroleum Geologists Bulletin, vol. 72, no. 6, pp. 649-663, 1988.

[38] S. Zhang, G. Zhu, and K. He, "The effects of thermochemical sulfate reduction on occurence of oil-cracking gas and reformation of deep carbonate reservoir and the interaction mechanisms," Acta Petrologica Sinica, vol. 27, no. 3, pp. 809-826, 2011.

[39] V. Schmidt and D. A. Mcdonald, "The role of secondary porosity in the course of sandstone diagenesis," in Aspects of Diagenesis, P. R. Schluger, Ed., SEPM Society for Sedimentary Geology, Oklahoma, Okla, USA, 1979.

[40] C. H. Moore, Carbonate Diagenesis and Porosity, Elsevier, New York, NY, USA, 1989. 

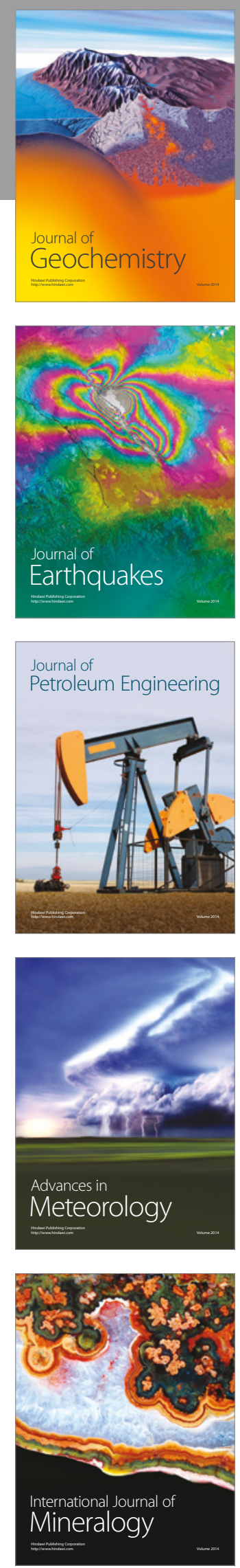
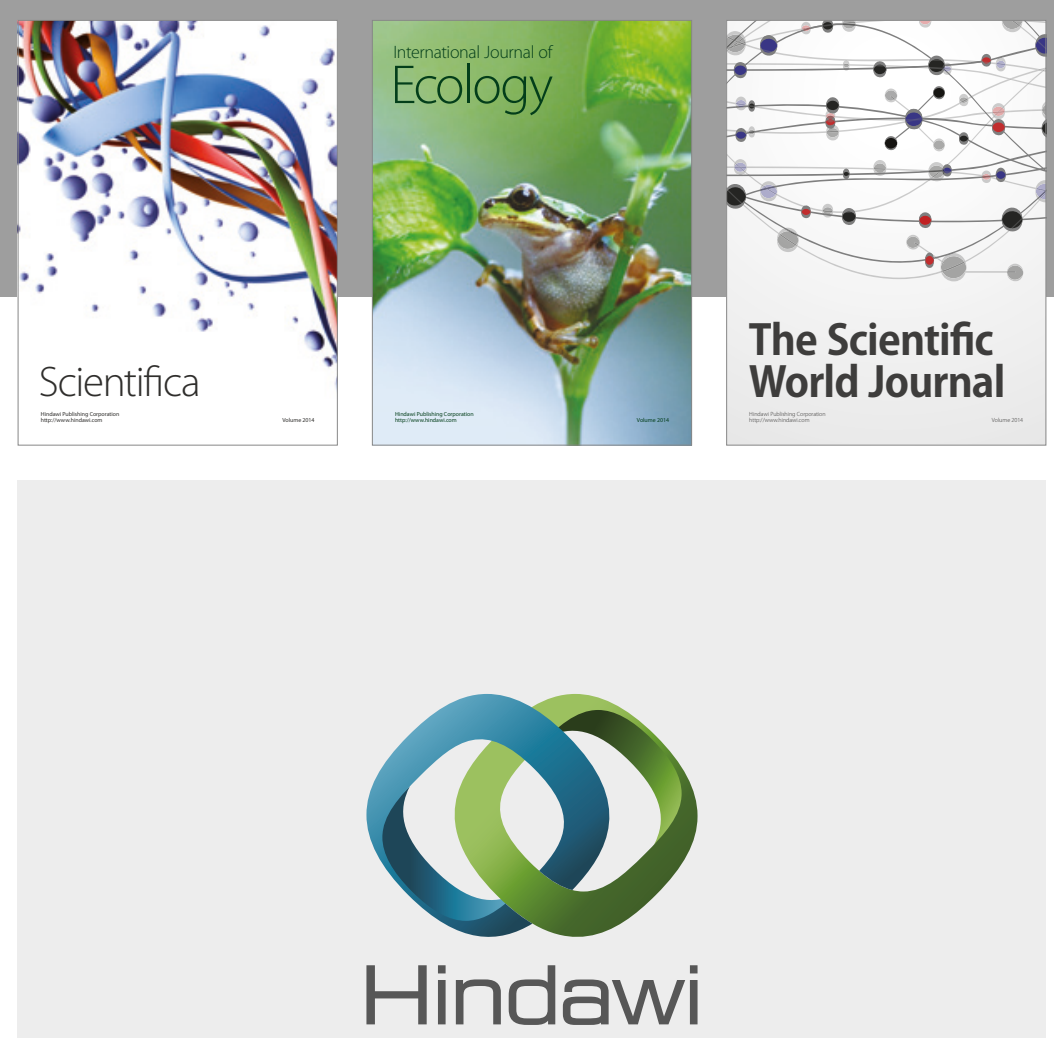

Submit your manuscripts at

https://www.hindawi.com
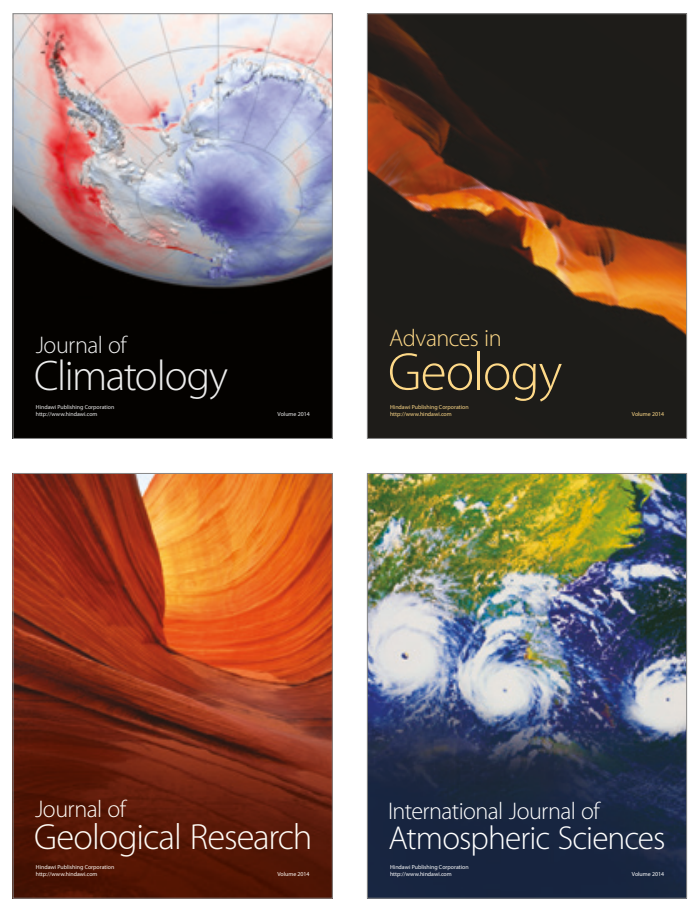

The Scientific

World Journal
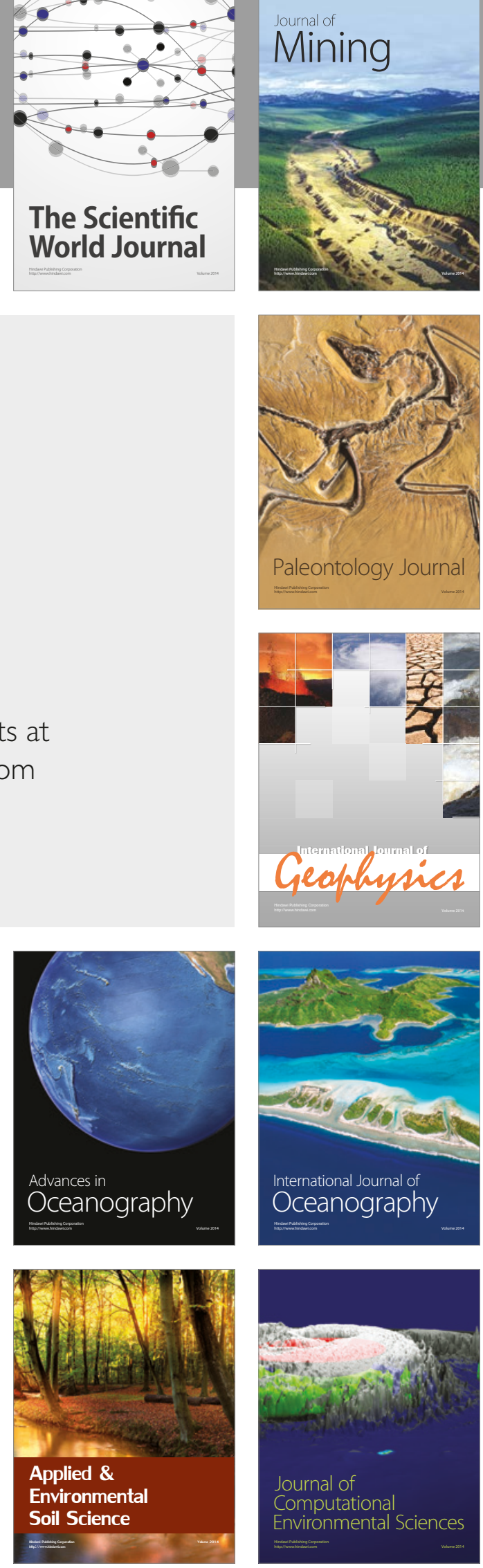